\title{
Direct Computation of Sound Radiation by Jet Flow Using Large-Scale Equations
}

R. R. Mankbadi

Lewis Research Center

Cleveland, Ohio

S.H. Shih and D.R. Hixon

Institute for Computational Mechanics in Propulsion

Lewis Research Center

Cleveland, Ohio

L.A. Povinelli

Lewis Research Center

Cleveland, Ohio

Prepared for the

33rd Aerospace Sciences Meeting

sponsored by the American Institute of Aeronautics and Astronautics Reno, Nevada, January 9-12, 1995

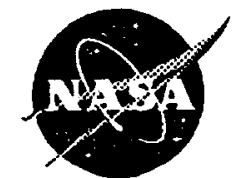

National Aeronautics and

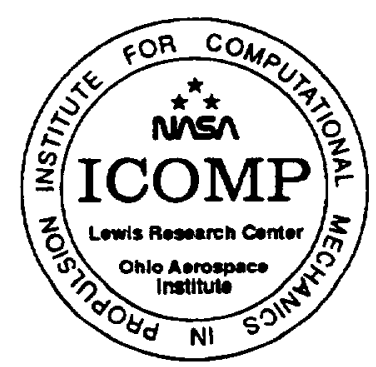





\title{
Direct Computation of Sound Radiation by Jet Flow Using Large-Scale Equations
}

\author{
R. R. Mankbadi* \\ NASA Lewis Research Center \\ Cleveland, Ohio 44135 \\ S. H. Shih** and D. R. Hixon**
Institute for Computational Mechanics in Propulsion
NASA Lewis Research Center
Cleveland, Ohio 44135 \\ L. A. Povinelli*** \\ NASA Lewis Research Center \\ Cleveland, Ohio 44135
}

\begin{abstract}
Jet noise is directly predicted using large-scale equations. The computational domain is extended in order to directly capture the radiated field. As in conventional large-eddy-simulations, the effect of the unresolved scales on the resolved ones is accounted for. Special attention is given to boundary treatment to avoid spurious modes that can render the computed fluctuations totally unacceptable. Results are presented for a supersonic jet at Mach number 2.1.
\end{abstract}

\section{Introdnction}

The recent growing interest in turbulence noise is largely due to efforts to develop a high-speed civil transport plane. The success of this new technology is contingent upon reducing its jet exhaust noise.The jet noise is generated by the time dependent flow fluctuations in the near field which are associated with pressure fluctuations that propagate to the far field producing the radiated sound. In theory, direct numerical simulation (DNS) based on the compressible Navier-Stokes equations provide both the flow fluctuations and the acoustic field. However, the resolution requirement for high-Reynolds number urbulent flows makes direct numerical simulation impractical due to current computer limitations. In

- Senior scientist and technical leader, CAA, Associate fellow ALAA

* Senior research associate, Member AIAA

*** Acting Chief, Intemal Fluid Mechanics Division, Fellow, AIAA large-eddy simulations, the full navier-Stokes equations are solved, while realizing that the smaller scales of turbulence can not be resolved for high-Reynolds number turbulent flows. Modelling is used to account for the effect of these unresolved scales on the resolved ones. It is believed that the large scale strucure is more efficient than the small scale structure in radiating sound [1-5]. This indicates that it is appropriate to perform large-eddy simulations to accurately capture the large scales of motion while modelling the sub-grid scale turbulence.

The use of large-eddy simulations (LES) as a tool for prediction of the jet noise source has been proposed by Mankbadi et al [6]. The fluctuating sound source in the near field was then used to obtain the far field sound through the application of Lighthill's theory. It was shown [6] that because of the non-compactness of the source and the noed to account for the retarded time, accurate application of Lighthill's theory requires, in turn. prohibitive computer storage. The present work is concemed with avoiding such techniques via direct extension of the computational domain to capture the radiated field. Large-scale equations are solved for both the sound and the acoustic fields. The Smagorinsty's model is used for simplicity. But further attention is needed for modelling the effect of the smaller scales on the larger ones, particularly for the acoustic disturbance. Careful attention is given in this paper to the boundary treatment. which is the main issue in predicting an accurate acoustic field.

\section{Goyerning_Equations}

The flow field of a supersonic jet is governed by the compressible Navier-Stokes equations, and can be decomposed into filtered and residual fields, namely 
$f=\mathbf{f}+\mathrm{f}^{\prime \prime}$

where an overbar denotes the resolved (filtered) field and a (") denoles the unresolved (subgrid) one. The mean of the filtered field is the mean of the total field. Upon substituting this spliuing in the full Navier-Stokes equations, the filtered compressible Navier-Stokes equations

$\therefore$ in cylindrical coordinates takes the form

$\frac{\partial Q}{\partial t}+\frac{\partial F}{\partial x}+\frac{1}{r} \frac{\partial}{\partial r}(r G)=S$

where

$Q=\left[\begin{array}{llll}\rho, & \bar{\rho}, & \rho \bar{v}, & \rho \bar{E}\end{array}\right]^{T}$

$F=\left[\begin{array}{c}\bar{\rho} \bar{u} \\ \rho+\bar{\rho} \bar{u}^{2}-\bar{\sigma}_{x x}-\tau_{x x} \\ \rho \bar{u} \bar{v}-\bar{\sigma}_{x I}-\tau_{x r} \\ \bar{\rho} \bar{u} \bar{I}-\bar{u} \bar{\sigma}_{x x}-\bar{v} \overline{\sigma_{x I}}-k_{\frac{\partial}{\partial x}} \bar{T}-c_{v} q\end{array}\right]$

$G=\left[\begin{array}{c}\bar{\rho} \bar{v} \\ \rho \bar{u} \bar{v}-\bar{\sigma}_{x I}-\tau \\ p+\rho \bar{v}^{2}-\bar{\sigma}_{r I}-\tau_{r I} \\ \rho \bar{v} \bar{I}-\bar{u} \bar{\sigma}_{x I}-\bar{v} \overline{\sigma_{I I}}-k_{\overline{I I}} \frac{\partial}{\bar{T}}-c_{v} q\end{array}\right]$

$S=\frac{1}{r}\left[\begin{array}{c}0 \\ 0 \\ p-\tilde{\sigma}_{\phi \phi}-\tau_{\phi \phi} \\ 0\end{array}\right]$

Here $Q$ is the unknown vector, $F$ and $G$ are the fluxes in the $x$ and $r$ directions, respectively, $S$ is the source term that arises in cylindrical polar coordinates; and $k$ is thermal conductivity. The total enthalpy is I, the total energy is $E$, and $\sigma_{i j}$ are the viscous stresses. This system of equations is coupled with the equation of state for a perfect gas. Here, a tilde denotes Favre fitering,

$\tilde{f}=\frac{\overline{p f}}{\bar{p}}$

The unresolved stresses $\tau_{\mathrm{ij}}$ appearing in equations (4-6) need to be modeled.

\section{Subrrid-Sole Modelling}

The Smagorinsky's model [7] was chosen to represent the effect of the subgrid-scale turbulence stresses.

$\tau_{\mathrm{ij}}=\mathrm{k}_{\mathrm{B}}\left(\delta_{\mathrm{ij}} / 3\right)-2 p v_{\mathrm{R}}\left(\tilde{S}_{\mathrm{ij}}-\frac{1}{3} \delta_{\mathrm{ij}} \overline{\mathrm{S}}_{\mathrm{mm}}\right)$

where $k_{z}$ is the kinetic energy of the residual turbulence. The strain rate of the resolved scale is given by

$\tilde{S}_{i j}=\frac{1}{2}\left(\frac{\partial \tilde{u}_{i}}{\partial x_{j}}+\frac{\partial \bar{u}_{j}}{\partial x_{i}}\right)$

The summation $S_{m m}$ is zero for incompressible flow, $v_{R}$ is the effective viscosity of the residual field.

$v_{R}=\left(C_{s} \Delta_{f}\right)^{2} \cdot \sqrt{2 S_{m n} S_{m n}}$

and $\Delta_{I}$ is the filter width given by

$\Delta_{\mathrm{f}}=\left(\Delta_{\mathrm{x}} \Delta_{\mathrm{r}}\right)^{1 / 2}$

For the heat equation, Edison [8] proposed the eddy viscosity model

$q=\bar{p} \frac{v_{R}}{\mathrm{Pr}_{\mathrm{r}}} \frac{\partial \tilde{T}}{\partial x_{k}}$

where $\mathrm{P}_{q}$ is the subgrid-scale turbulent Prandtl number, which can be taken as 0.5 . Smagorinsky's constant $C_{8}$ in equation (10) is given by Reynolds [9] as 0.23 . In the presence of mean shear, however, this value was found to cause excessive damping of large-scale fluctuations. and in his simulation of turbulent channel flow, Deardor. ff [10] used $C_{8}=0.1$. Piomelli et al. [11] found the optimum value of $C_{s}$ to be 0.1 . This value was used herein.

Although Smagarinsky's model is one of the simplest models, it assumes a balance between the subgridscale energy production and its dissipation. This balance may not be true in several sinations. Further work is peeded for developing more appropriate subgrid-scale models for jet noise predictions.

\section{Numerical Scheme}

The imporance of the dispersion and dissiparion of a given scheme, used in connection with the computational aeroacoustics, was highlighted by Hardin [12]. Both effects are crucial in computational aeroacoustics, and can render the computed unsteady part of the solutica complesely unacceptable. As such, high-order accurate schemes are required for problems in computational aeroscoustics.

A fourth-order accurate in spece, second-order accurile in time scheme is used, which is an extension of the MacCormack scheme by Goulieb and Turkel [13]. Man- 
kbadi et al. [6] used this scherne to study the structure of axisymmetric supersonic jet flow. Ragab and Sheen [14], and Farouk, Oran and Kailasanath [15] have also successfully applied this scheme for the study of nonlinear instability problems in plane shear layers. Sankar, Reddy and Hariharan [16] performed a comparative study of various numerical schemes for seroacoustics applications, and found that this scheme offers high spatial ac-

$\therefore \quad$ curacy. In this scheme, the operator is split into two onedimensional operators and applied in a symmetric way to avoid biasing of the solution:

$$
Q^{n+2}=L_{2 x} L_{2 r} L_{1 r} L_{1 x} Q^{n}
$$

where $L$ represents the one-dimensional operator. Each operator consists of a predictor and a corrector steps, and each step uses one-sided differencing:

Predictor:

$$
Q_{i}^{n+\frac{1}{2}}=Q_{i}^{n}-\frac{\Delta t}{6 \Delta x}\left(7 F_{i}-8 F_{i-1}+F_{i-2}\right)^{n}(
$$

\section{Corrector:}

$$
\begin{aligned}
& Q_{i}^{n+1}=\frac{1}{2}\left[Q_{i}^{n}+Q_{i}^{n+\frac{1}{2}}\right. \\
& \left.+\frac{\Delta t}{6 \Delta x}\left(7 F_{i}-8 F_{i+1}+F_{i+2}\right)^{n+\frac{1}{2}}\right]
\end{aligned}
$$

and likewise for the radial direction. The scheme becomes fourth-order accurate in the spatial derivatives when alternated with symmetrical variants. $L_{\text {et }} L_{1}$ be the one-dimensional operator with forward difference in the predictor and backward difference in the corrector, then $\mathrm{L}_{2}$ will be the one-dimensional operator with backward difference in the predictor and forward difference in the corrector. At the computational boundaries, flux quantities outside the boundaries are needed to compute the spatial derivatives, and these can be obtained using thirdorder extrapolation based on data from the interior of the domain.

\section{Boundary Conditions}

Special attention is given berein to boundary treatment in order to avoid non-physical oscillations that can render the computed acoustic field unacceptable. Several boundary treatments were considered $[17,18]$. The boundary treament discussed below were found to be stable, non-reflecting, and most suitable for the present jet computations.

\subsection{Inflow Boundary}

At the inflow boundary $(x=0)$, the radial boundary is split into hydrodynamic disturbance and radiation regimes, which are treated differently according to the physics involved.

\section{5.hHydrodynamic Disturbance Regime}

At the inflow boundary, a small disturbance is introduced. This disturbance is assumed to be mainly hydrodymamic in nature, and is specified from the centerline to $\mathrm{r} / \mathrm{D}=2$. To a first approximation, the inflow disturbances is assumed to be small such that the linear stability theory applies. A narmal mode decomposition for the disturbance is assumed in the form:

$$
\left[u^{\prime} v^{\prime} p^{\prime} p^{\prime}\right]=\Re\left\{\Phi(r) e^{i(\alpha x-\omega t)}\right\}
$$

The governing equations in this case can be reduced to On-Sommerfeld equation, which are solved to obtain the complex wave number $\alpha$ as the eigenvalue corresponding to the frequency $\omega$ and the radial functions $\Phi(r)$ as the corresponding eigenfunctions.

$$
\Phi(r)=[\hat{u}(r) \hat{v}(r) \hat{p}(r) \hat{\rho}(r)]
$$

To obtain the disturbance solution a mean flow must be specified. In the present work, the analytical functions proposed by Tam and Burton [19] to fit the experimental data of Trouth and McLaughlin [20] were used. The mean axial velocity is given by

$$
\begin{aligned}
& U=1 \quad \text { for } r<h \\
& U=\exp \left[-\ln (2)\left(\frac{r-h(x)}{b(x))}\right)^{2}\right] \text { for }>h
\end{aligned}
$$

where $b(x)$ is the half-width of the annular mixing layer, and is fitted to the experimental data. The radius of the potential core, $h(x)$, is related to $b(x)$ through the conservation of momentum:

$$
\int_{0}^{\infty} p U^{2} r d r=\frac{1}{2}
$$

Velocities are normalized by the streamwise velocity at the jet exit centerline; density by the exit centerline density; and distances by the nozzle radius. The static pressure is uniform in the radial direction. The total tempernture is assumed uniform, which provides the distribution for the static temperature

$$
T_{0}=T+\frac{u^{2}}{2 p c_{p}}
$$

where $c_{p}$ is the specific heat under constant pressure. The 
density is oblained from the equation of state.

For the supersonic regime, all characteristics travel in the flow direction. Thus the primitive variables are given at $x=0$ as outlined above. An extrapolation is needed for the two points outside the domain $(x<0)$. Rather than using the conventional polynomial extrapolation, we choose the extrapolation function to fit the linear $\because$ growth rate, namely:

$u(x, r)=A e^{\beta x} g\left\{\hat{u}(r) e^{i(\alpha, x-\omega t)}\right\}$

where $\beta$ represents the growth rate that can be obtained either from the linear theory or from the interior solution.

In the subsonic regime, the following three characteristics are specified according to the linear stability solution:

$$
\begin{aligned}
& p_{t}+p c u_{t}=C_{1} \\
& p_{t}-c^{2} p=C_{2} \\
& p c v_{t}=C_{3}
\end{aligned}
$$

The fourth characteristic is outgoing and is obtained from the interior solution:

$p_{t}-p c u_{t}=C_{4}$

The four characteristic equations are then solved together to obtain the time derivatives of the variables, which are used to update the solution at the inflow boundary.

\subsection{Radiation regime}

In the radiation regime ( $r / D>2)$, the conventional acoustic radiation condition applies:

$$
Q_{t}=-\Gamma(\theta)\left[\frac{\pi}{R} Q_{x}+\frac{r}{\bar{R}} Q_{T}+\frac{Q}{\bar{R}}\right]
$$

where:

$$
\begin{aligned}
& Q=[u \vee p \rho] \\
& R=\sqrt{x^{2}+r^{2}} \\
& r(\theta)=c\left[\frac{x}{R} M+\sqrt{1-\left(\frac{r}{R} M\right)^{2}}\right]
\end{aligned}
$$

and $M$ is the local Mach number, $c$ is the sonic velocity. The spatial derivatives which appear in equation (24) are evaluated in an identical manner as the inner flow derivatives.

\subsection{0uthos. Boundary}

The outflow treatment is based on the asymptotic analysis of the linearized equations as given by Tam and

Webb [21]. The pressure condition is the same as that obtained by Bayliss and Turkel [22], Enquist and Majda [23], and Hariharan and Hagstrom [24], namely:

$P_{t}=-r(\theta)\left[\frac{X}{R} P_{X}+\frac{T}{R} P_{r}+\frac{P}{R}\right]$

However, for updating the rest of the primitive variables. Tam and Webb have shown that the momentum and continuity equations should be used to account for the presence of entropy and vorticity waves at the outflow boundary. The spatial differencing used in the inner code is employed to evaluate the derivatives which appear in equation (26).

For the outflow regime of large radius with the local Mach number less than 0.01 , the outflow condition is replaced by the conventional radiation condition of Section 5.1.2.

\section{0uter Radial Boundary}

At the outer radial boundary $\left(r=r_{\max }, 0<x<\alpha_{\max }\right)$, the conventional radiation boundary condition of Section 5.12. is used.

\subsection{Centerline Boundary}

The results presented herein are for axisymmetric disturbance, for which the boundary condition at $r=0$ can be stated as

$\frac{\partial}{\partial r}\left[\begin{array}{lll}u & p & p\end{array}\right]=0$

$v=0$

The centerline treatment for non-axisymmetric disturbances is not obvious, and is addressed in a separate paper by Shih et al [25]

\section{Resmlts and Dismasion}

The numerical results of the flow and acoustic fields of a cold, nearly perfectly expended axisymmetric supersonic jet of Mach number 2.1 will be presented. The tocal temperature of the jet is $294^{\circ} \mathrm{K}$, and the jet exit pressure is $0.0515 \mathrm{~atm}$. The Reynolds number based on exit conditions is approximately 70000 . In the present calculation, the jet is excited at a Strouhal number of 0.2 with the Strouhal number defined as $S t=\mathbb{D} / \mathrm{U}_{0}$, where $\mathrm{D}$ is the nozzle exil diameter and $U_{0}$ is the jet exit centerline vebocity. The computed results will be compared with the analytical solutions of Tam and Bunon [19] and the experimental measuremenes of Troulu and McLaughlin [20]. 
The computational domain for this problem extends axially from $x / D=2.5$ to $x / D=35$, and radially from centerline to $\mathrm{r} / \mathrm{D}=32$, as shown in figure 1 . Due to the steep mean flow gradient encountered at the jet exit, the computational grid was begun at an axial distance $x / D=2.5$ from the acuial jet exit. The appropriate boundary treatments are also indicated on this figure. The computational grid consists of 391 equally spaced points in the axial

$\therefore$ direction. In the radial direction, 150 points are used and stretched between centerline and $\mathrm{r} / \mathrm{D}=2.5$ with concentration of grid points around $r / D=0.5$. Between $r / D=2.5$ and $r / D=16,130$ equally spaced points are used with a spacing equal to that of the last stretched points.

Figure 2 shows the instantaneous distribution of $p$. $p, u$ and $v$. As one can see that the solution is clean from boundary reflections. The wave-like nature of the flow field is evident The sound pattern seems to peak at angle influenced by the streamwise position where the fluctuation reaches a maximum. The spreading of the jet can be seen in the instantaneous axial velocity and density distributions.

Figure 3 shows the mean flow Mach number profiles at various streamwise positions. The computed Mach number profiles indicate the spreading of the jet, but it is underpredicted when compared with the measurements. This might be atributed to the fact that the present calculation is axisymmetric, and the uncertainty of the subgrid-scale model used as was discussed in section 3. Secondly, the present inflow boundary treatment might need to be modified to allow for specifying entrainment.

Figure 4 shows contours of the root-mean-square values of the axial momentum and pressure distributions. The preferred emission is evident in the figure.

Figures 5 and 6 show the axial development of the axial momentum and pressure fluctuations on the nozale lip line. The computed results are compared with the measurements of Troutt and McL aughlin [20]. As can be seen in this figure, the computed curve peaks at about 5 diameters downstream of the measured peak. It implies that the noise source of the calculated results is located somewhat downstream of the measured peak. In the experiment of Troutt and McLaughlin [20], instability waves were excited by a single point glow discharge mounted flush near the nozzle exil. However, as poinied out by Trouts and McLaughlin, the messurements showed that the excited motion of the jet is dominated by the first helical mode in addition to the axisymmetric mode. It is expected that the peak of the curve would move upstream if the axisymmetric and the helical modes excitations are applicd simultaneously.

Figures 7 and 8 shows modial profiles of the axial momentum and pressure fluctuations in the jet for several downstream positions. The radial peak of the fluctuation amplitude moves toward the jet centerline, and the width of the shear layer increases with downstream locations. The profiles at $x / D=5$ in both figures are typical of the eigenfunctions of linear stability analysis.

Figures 9 and 10 show the frequency spectra of axial velocity and pressure at several downstream locations in the center of shear layer. The spectra indicates that the dominant frequency is that of the fundamental forcing frequency and the subsequent harmonics. The amplitudes of the fundamental and harmonics decay at downstream location, but not so rapidly as observed in the measurements.

Figure 11 shows the sound pressure level distribution in the far field for the present calculation, the axisymmetric mode of Tam, and Burton [19], and the experimental measurements of Troutt and McLaughlin [20]. It is seen that the patterns of the sound pressure level contours are all qualitatively similar. The lobed appearance of figure 11a indicates that the present calculation predicts a strong noise radiation in a direction at approximately $30^{\circ}$ from the location of the maximum fluctuation. However, the present results show a downstream shift of the lobes when compared to the analytical solutions and experimental measurements. As pointed out in the discussion of figure 5 , the calculated disturbance peaks downstrieam of the measured data and the spreading is underpredicted. This implies that the field shape of the calculated sound pressure level would be displaced downstream relative to Troutr and McLaughlin's observations.

Figure 12 shows the calculated and measured sound field directivity at a circle of radius 24D with center at the jet exit centerline. The angle is measured from the jet exil centerline. The calculated peak occurs around 15 degrees, which is smaller than the measured one. This is we to the downstream shifting of the field pattern of the overall sound pressure level, as was discussed in figure 11.

\section{Z. Conclusions}

Direct prediction of jet noise seems to be feasible for the axisymmetric case. In the large-scale simulation presented berein, the computational domain is extended to capture the radiated field, while modelling the effect of the smaller scales on the larger ones. However, careful 
autention is needed as was done herein, 10 boundary trealment, which becomes a serious issue in computing the acoustic field. The only limitation of large-scale simulation as compared to direct numerical simulation is that the smaller scale is not predicted. However, it is believed that the larger seales are more effective than the smaller scales in emitting sound. In conventional large-eddy simulation, the objective is the prediction of the mean flow field. But, herein, the objective is the fluctuation field Thus, careful attention is given to the algorithm used and boundary treatment for handling wave-type solutions.

Results presented for the axisymmetric field of Mach number 21 jet with single frequency distumbance at the inflow exhibit features consistent with the observations. Three dimensional effects are needed to produce jet spreading rate consistent with the observation. The small scale modelling might also need crucial attention, not only for adequate spreading of the jet, but also for extension to acoustic disturbances. The predicted acoustic field, however, seems to be in qualitative agreement with the observation. As previously pointed out $[19,20]$, the aximuthal modes seem to be responsible for a higher peak emission angle as compared to the axisymmetric case.

\section{References}

1. Seiner, J. M., MeLaughlin, D. K and Liu, C. H., "Supersonic Jet Noise Generated by Large-Scale Instabilities," NASA TP-2072, September, 1982.

2. Zaman, K. B. M. Q., "Flow Field and Near and Far Sound Field of a Subsonic Jet," Journal of Sound and Vibration, Vol. 106, pp. 1-6, 1986.

3. Mankbadi, R. R. and Liu, J. T. C., "Sound Generated Aerodynamically Revisited Large-Scale Strucwres in a Turbulent Jet as a Source of Sound," Philos. Trans. Royal Society of London A, Vol. 311, pp. 183-217, 1984.

4. Mankbadi, R. R., The Self Noise from Ordered Structures in a Low Mach Number Jet," Journal of Applied Mechanics, Vol 57, pp. 241-246, 1990.

5. Mankbadi, R. R, "Dynamics and Control of Coherent Seructure in Turbulent Jets," Applied Mechanics Reviews, Vol. 45, No. 6, pp. 219-247, 1992.

6. Mankbadi, R. R, Hayder, M. E. and Povinelli, L. A., "The Structure of Supersonic Jet Flow and Its Radiated Sound," ALAA Journal, Vol. 32, pp. 897-906, 1994.

7. Smagorinsky, J., "General Circulation Experiments with the Primitive Equations, I The Basic Experiment," Monthly Weather Review, Vol. 91. pp. 99. 164, 1963.
8. Edison, T. M., "Numerical Simulation of Turbulent Raykeigh-Bernard Problem Using Numerical Subgrid Modelling," Joumal of Fluid Mechanics, Vol. 158, pp. 245-268, 1985.

9. Reynolds, W. C., "The Potential and Limitations of Direct and Large Eddy Simulations," Whither Turbulence?: Turbulence at the Crossroads. Proceedings of the Workshop. J. L. Lumley, ed., SpringerVeriag. New York, pp. 313-342, 1989.

10. Deardorff, J. W., "Numerical Sudy of Three-Di. mensional Turbulent Channel Flow at Large Reynolds Number," Journal of Fluid Mechanies, Vol. 41, pp. 453-480, 1970.

11. Piomelli, U., Moin, P., and Ferriger, J. H., "Model Consistency in Large Eddy Simulation of Turbulent Channel Flows," Physics of Fluids, Vol. 31, pp. 1884-1891, 1988.

12. Hardin, J. C. "Recent Insights into Computational Aero-Acoustics," in Computational Aero- and Hydro-Acoustics, edited by R. R. Mankbadi, A. S. Lyrintzis, O. Baysal, L A. Povinelli, M. Y. Hussaini, FED-Vol. 147, pp. 1, 1993.

13. Goctlieb, D. and Turkel, E, "Dissipative Two-Four Methods for Time-Dependent Problems," Mathematics of Computation, Vol. 30, No. 136, pp. 703. 723, 1976.

14. Ragab, S. A and Sheen, S., The Nonlinear Development of Supersonic Instability Waves in a Mixing Layer," Physics of Fluids A, Vol. 4, pp. 553-566, 1991.

15. Farouk, B., Oran, E. S. and Kailasanath, K. 'Numerical Simulations of the Structure of Supersonic Shear Layers," Physies of Fluids A, Vol. 3, pp. 2786-2798, 1991.

16. Sankar, L. N, Reddy, N. N. and Hariharan, N., "A Comparative Sudy of Numerical Scheme for AeroAcoustic Applications," in Computational Aeroand Hydro-Acoustics, edited by R. R. Mankbadi, A. S. Lyrintzis, O. Baysal, L. A. Povinelli, M. Y. Hussaini, FED-Vol 147, pp. 1, 1993.

17. Hixon, R, Shih, S. H., and Mankbadi, R. R. "Evaluation of Boundary Conditions for Compunational Aeroscoustica." AIAA Paper 95-0160, Reno, Nevada, Jan. 1995.

18. Scoth, J. N., Mankbadi, R. R., Hayder, M. E., and Hariharan, S. I., "Outflow Boundary Condicions for the Computational Analysis of Jet Noise," AIAA Paper 93-4366, 1993.

19. Tam, C.K. W. and Burton, D. E, "Sound Generated by Instability Waves of Supersonic Flows, Pan 2: Axisymmetric Jets," Jourmal of Fluid Mechanics, Vol. 138, 1984, PP. 273-295, 1984.

20. Troutt, T. R. and McLaughlin, D. K. "Experiments on the Flow and Acoustic Properties of a Moderate 
Reynolds Number Supersonic Jet," Joumal of Fluid Mechanics, Vol. 116, PP 123-156, 1982.

21. Tam, C. K. W. and Webb, J. C., "Dispersion-Relation-Preserving Finite Difference Schemes for Computational Acoustics, "Joumal of Computational Physics, Vol. 107. pp. 262-281, 1993.

22. Bayliss, A. and Turkel, E., "Far Field Boundary Condition for Compressible Flows," Joumal of Computational Physics, Vol. 48, pp. 182-199, 1982.
23. Enquist, B. and Majda, A., "Radiation Boundary Conditions for Acoustic and Elastic Wave Calculations," Communications on Pure and Applied Mathematics, Vol. 32, No. 3, pp. 313-357, 1979.

24. Hagstrom, L. and Hariharan, S. I., "Far Field Expansion for Anisotropic Wave Equations," Computational Acoustics, Vol. 2, 1990.

25. Shih, S. H., Hixon, R. and Mankbadi, R. R.,"Three Dimensional Structure in a Supersonic Jet Behavior Near Centerline," AIAA Paper 95-0681, Reno, Nevada, January, 1995.

Acoustic Radiation

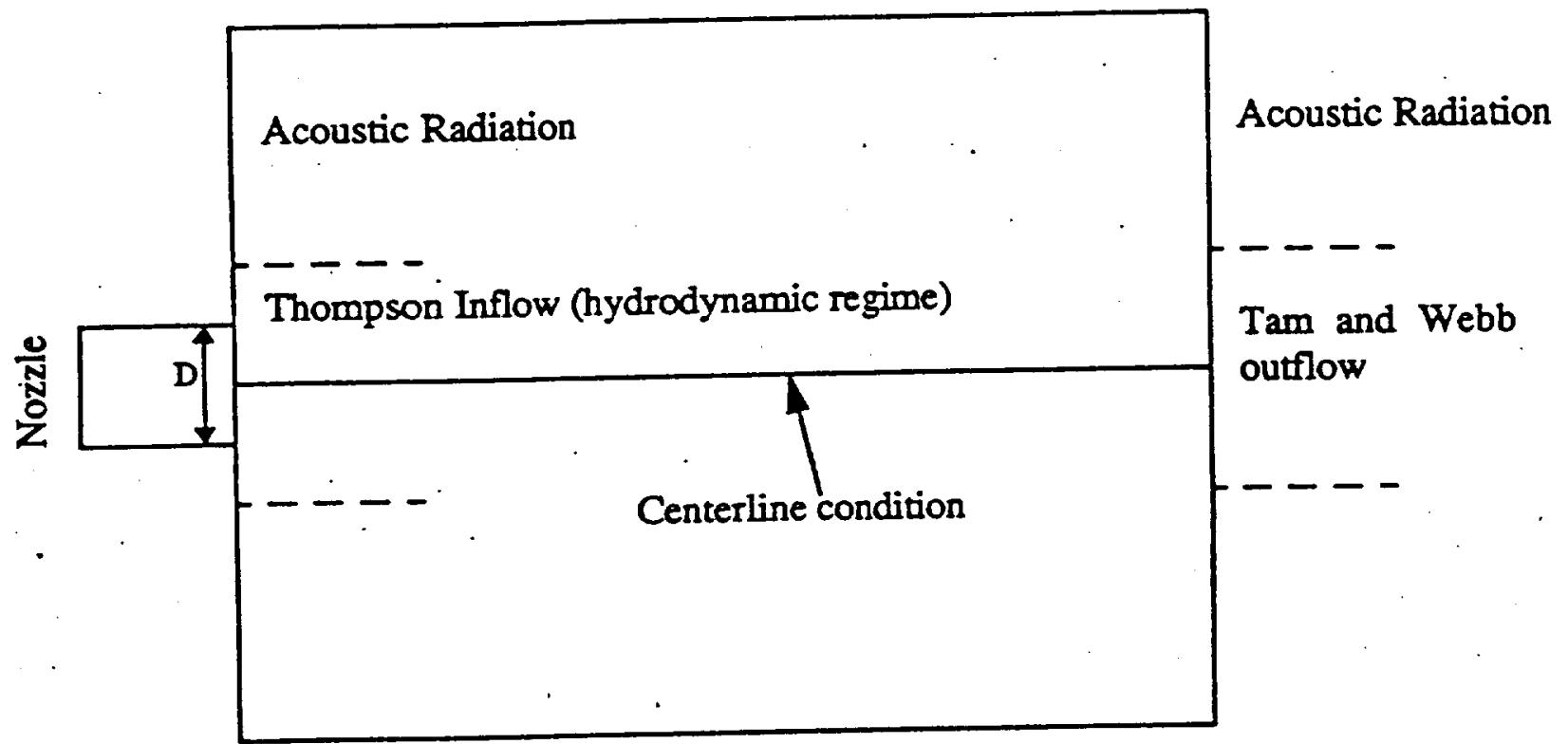

Acoustic Radiation

Fig. 1 Computational Domain 

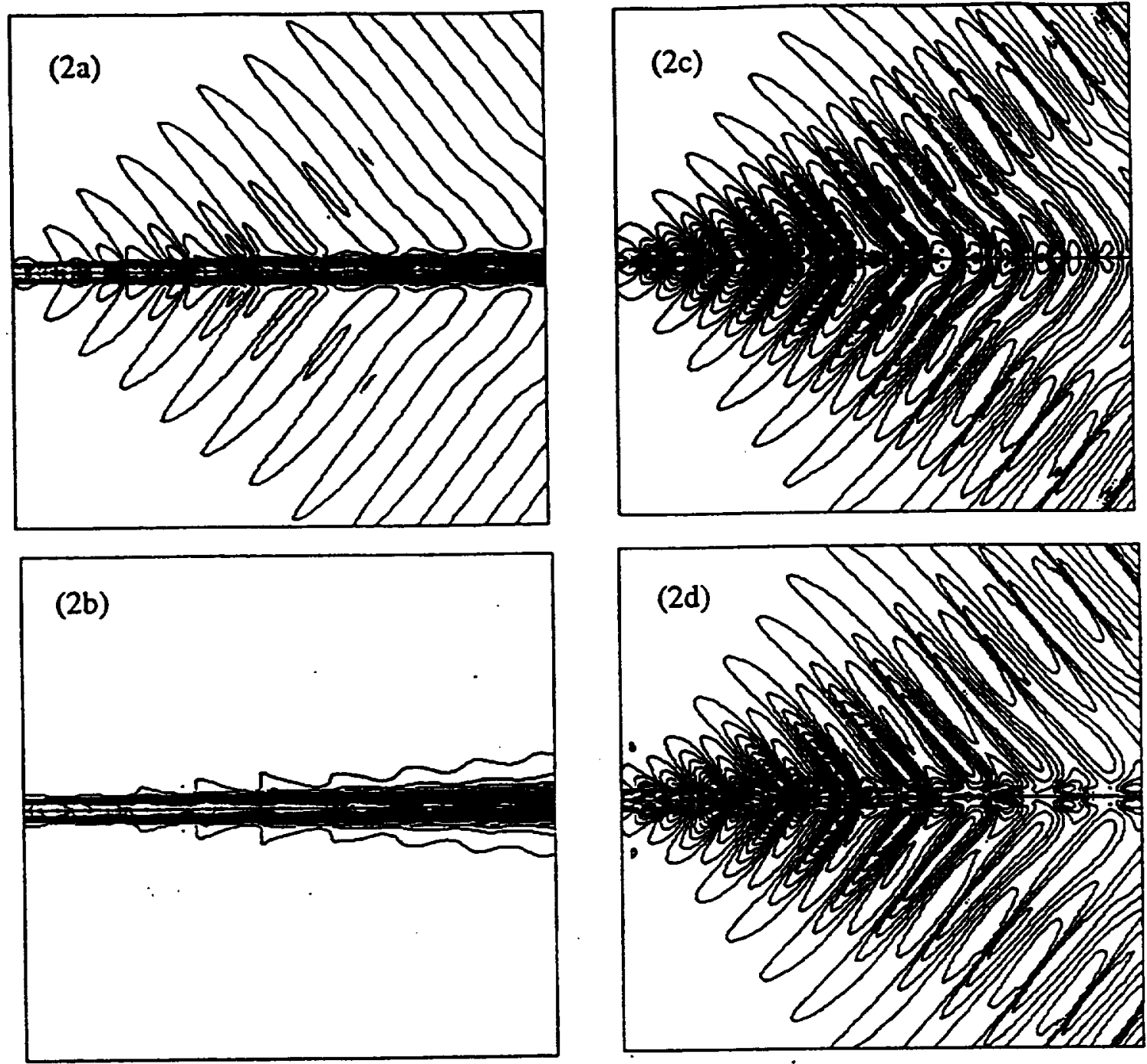

Fig. 2 Instantaneous distributions of (a) density (b) axial velocity (c) pressure (d) radial velocity.

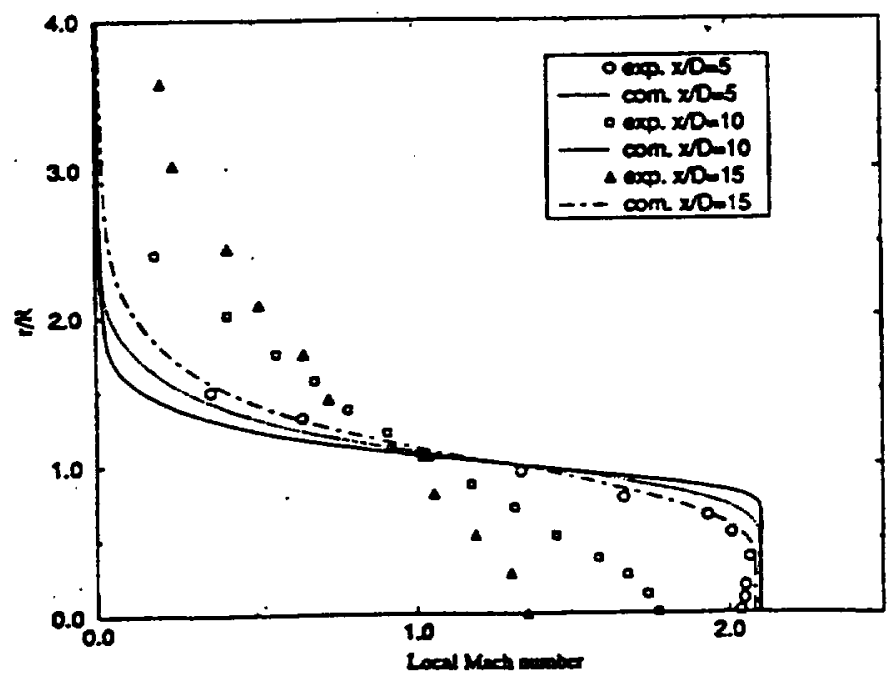

Fig. 3 Mean Mach number profiles at various streamwise positions. 

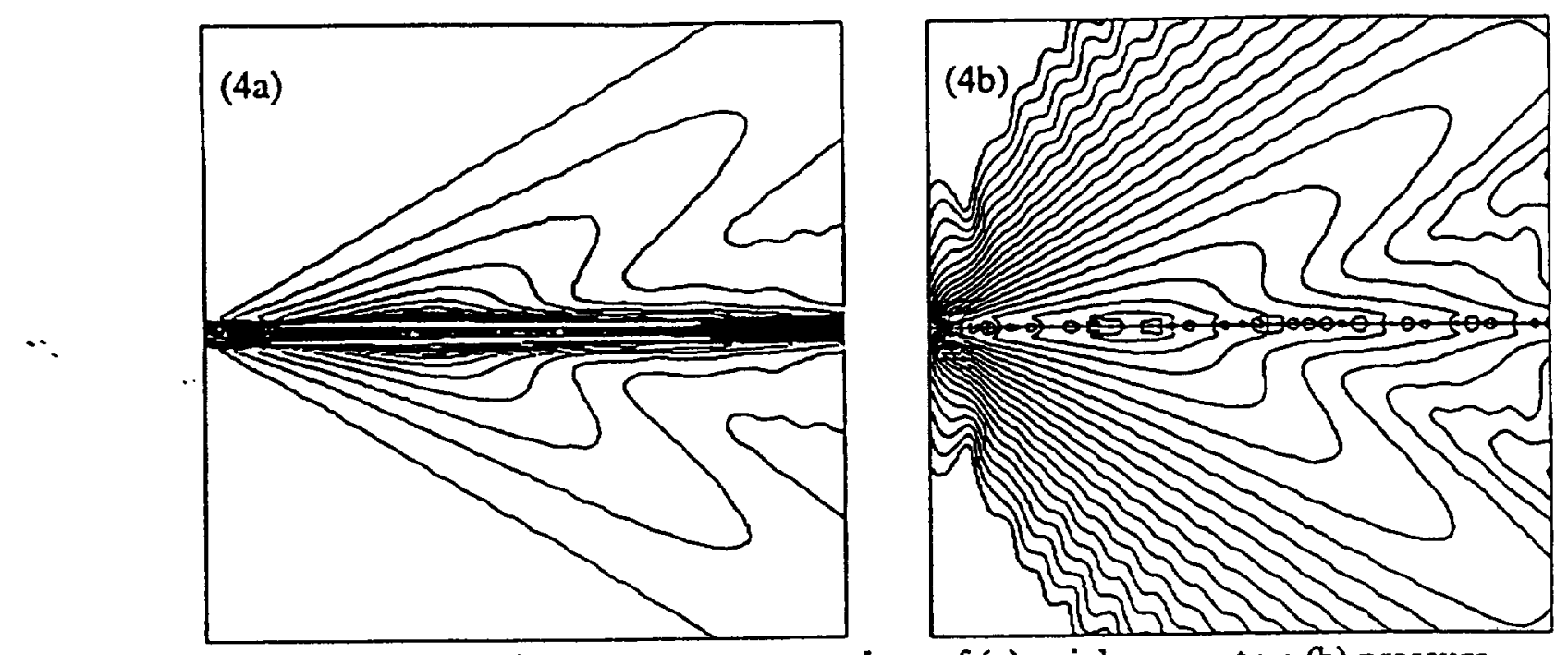

Fig. 4 Contours of root-mean-square values of (a) axial momentum (b) pressure.
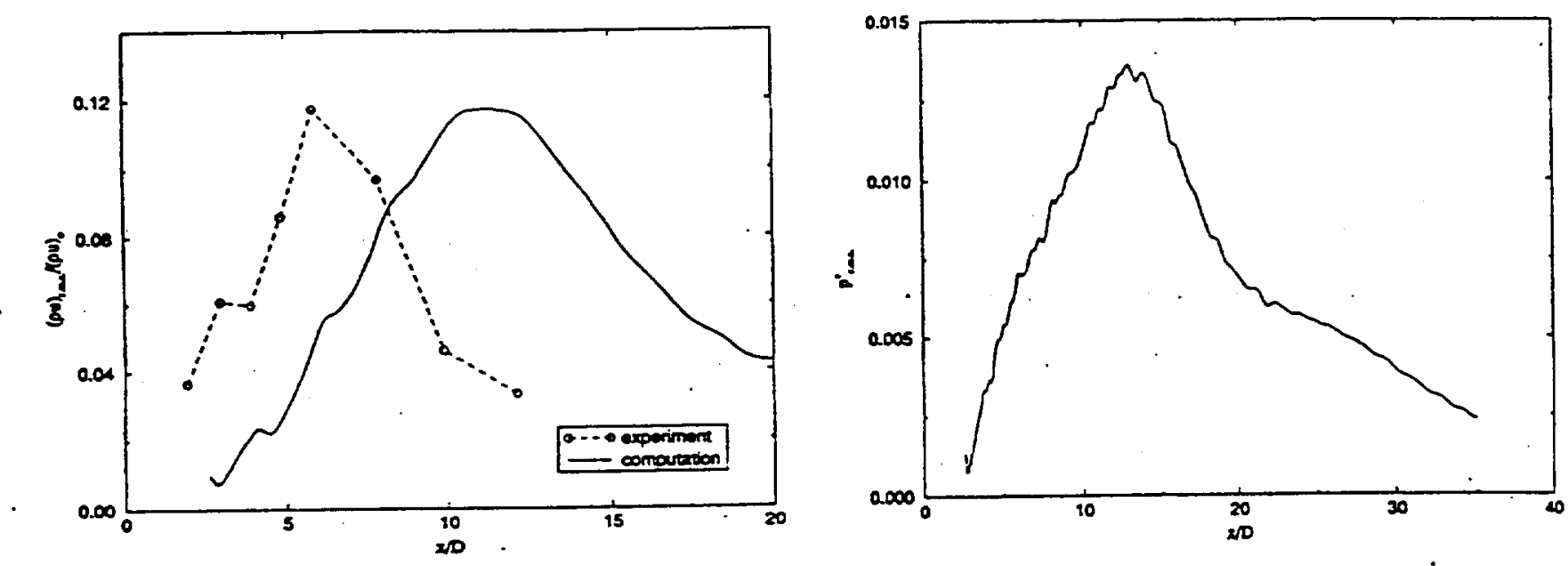

Fig. 5 Root mean square values of axial momen-

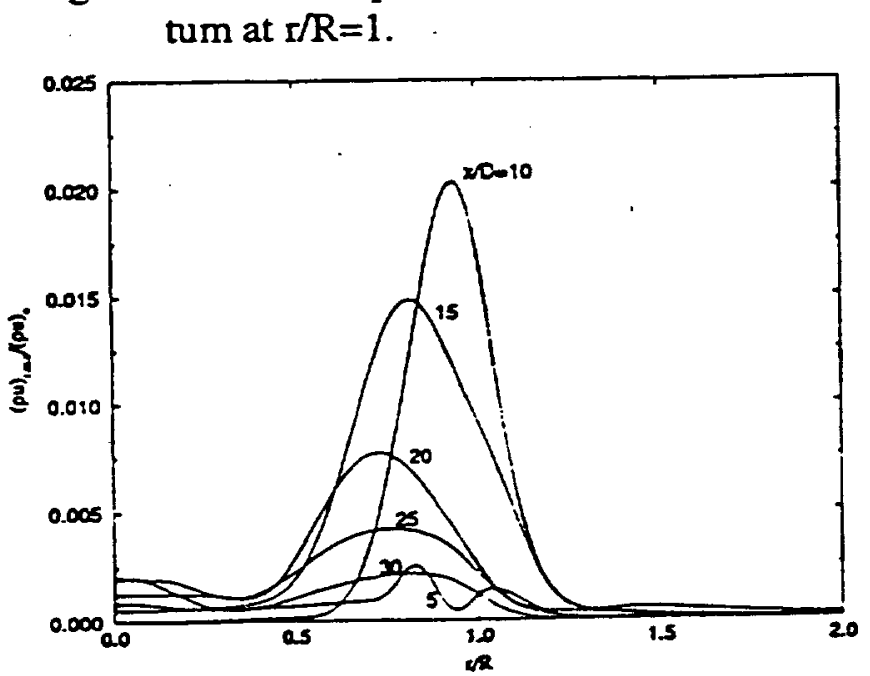

Fig. 7 Radial profiles of root-mean-square values of axial momentum.

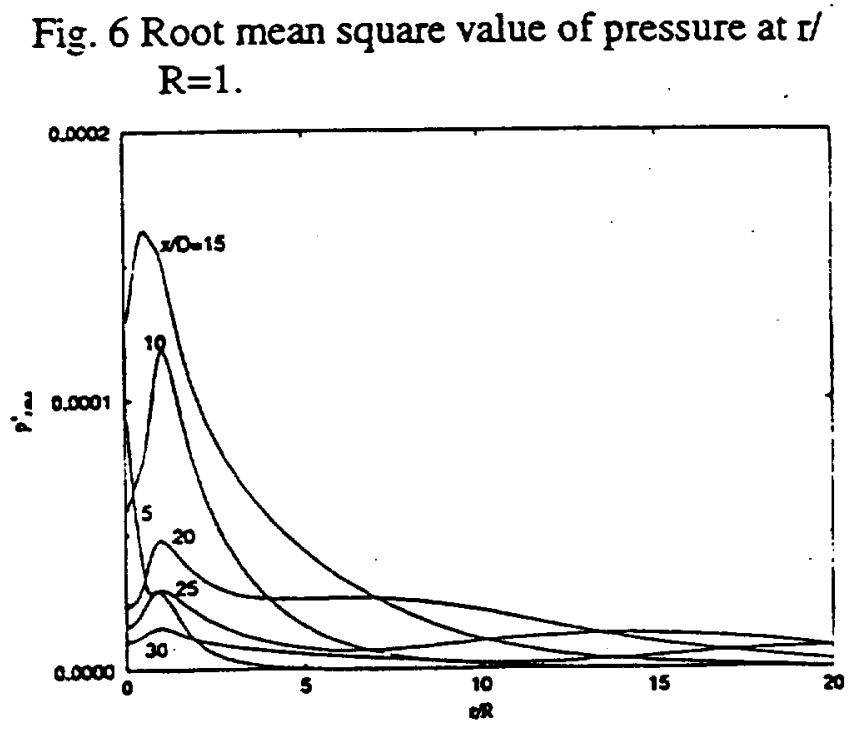

Fig. 8 Radial profiles of root-mean-square values of pressure. 


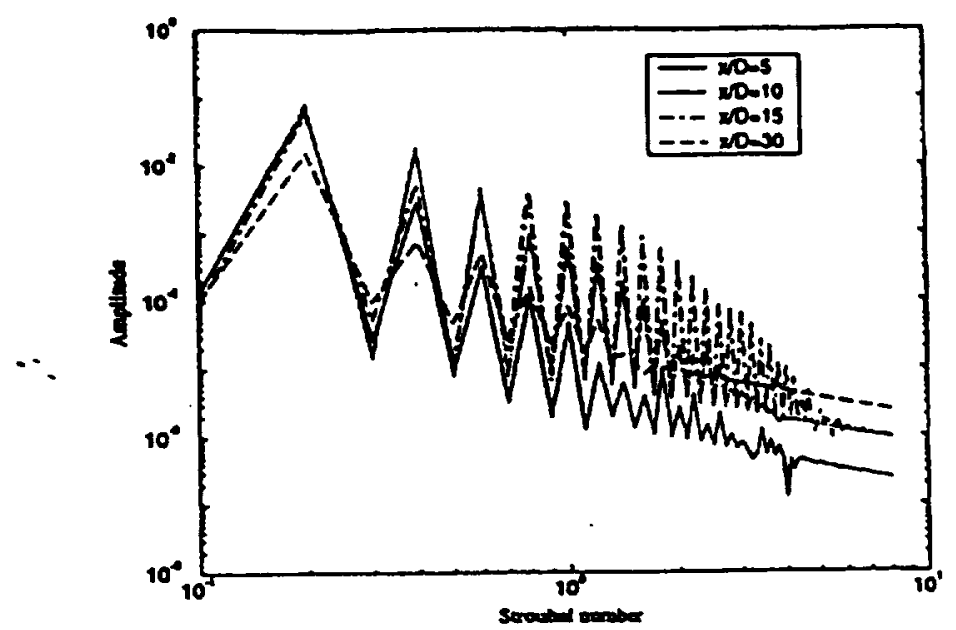

Fig. 9 Axial velocity spectra in the shear layer, $\mathrm{rl}$ $\mathrm{D}=0.5$.

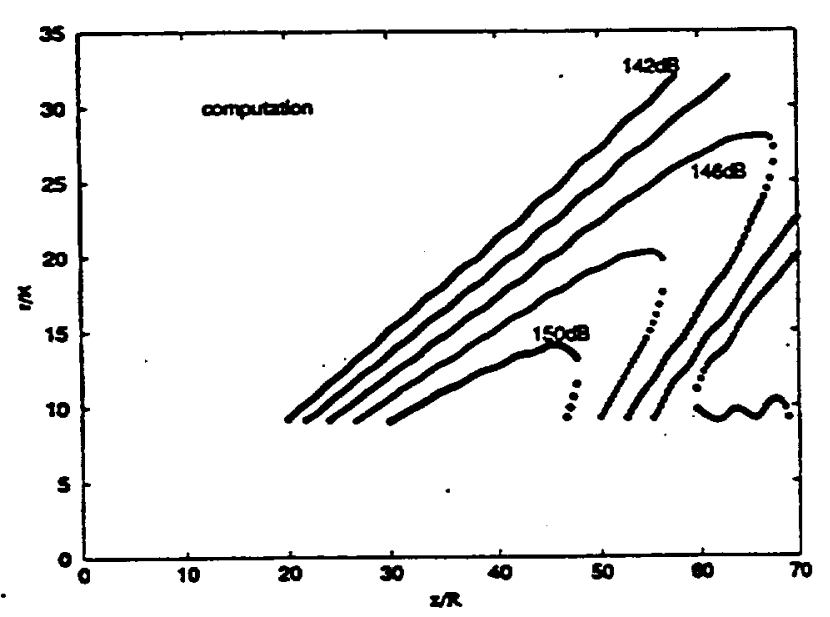

Fig. 11a Sound pressure level contours for present calculation.

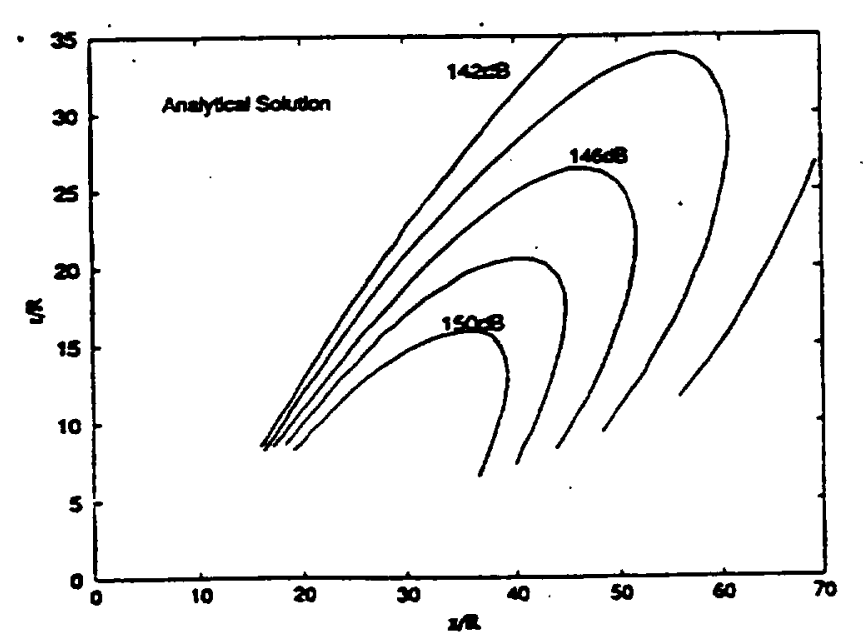

Fig. 11c Sound pressure level contours for Tam and Burton's analytical solution.

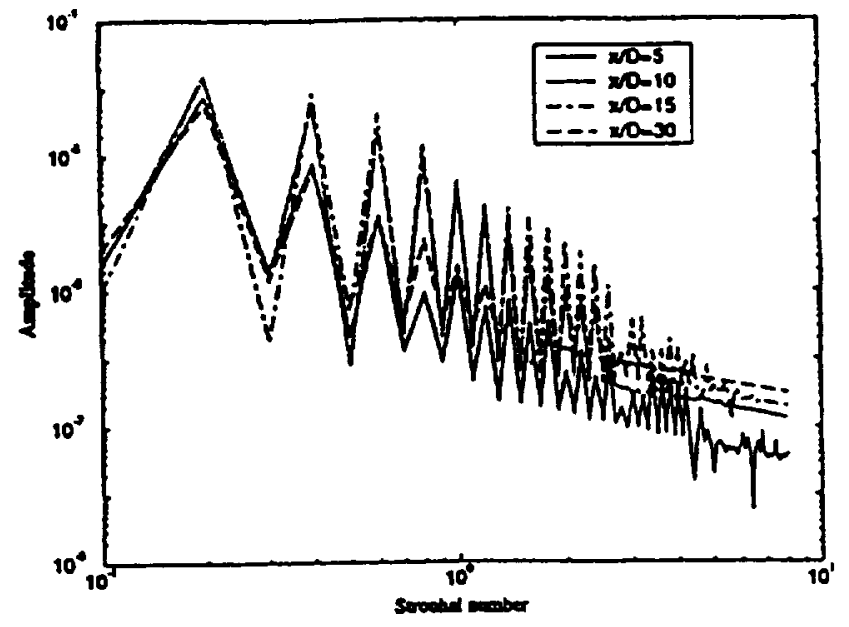

Fig. 10 Pressure spectra in the shear layer, r/ $\mathrm{D}=0.5$.

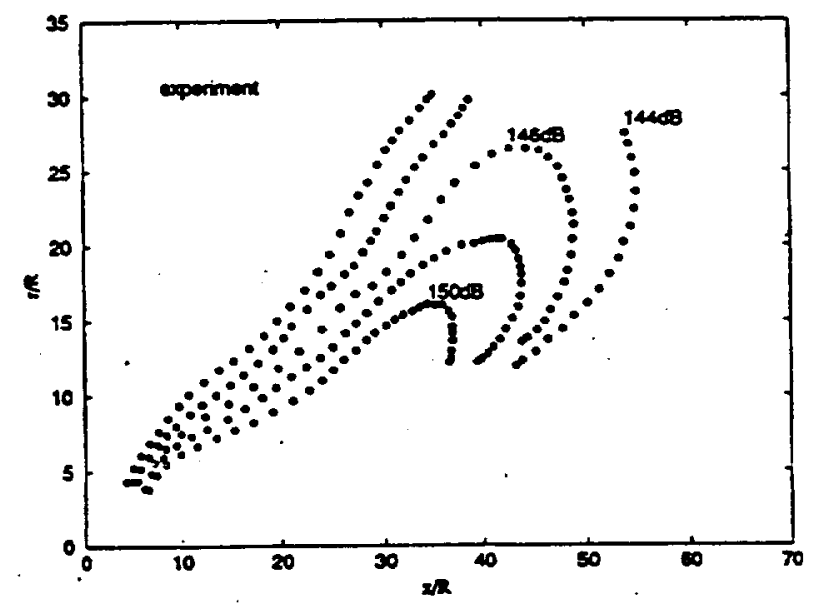

Fig. $11 \mathrm{~b}$ Sound pressure level contours for Troutt and McLaughlin's experiment.

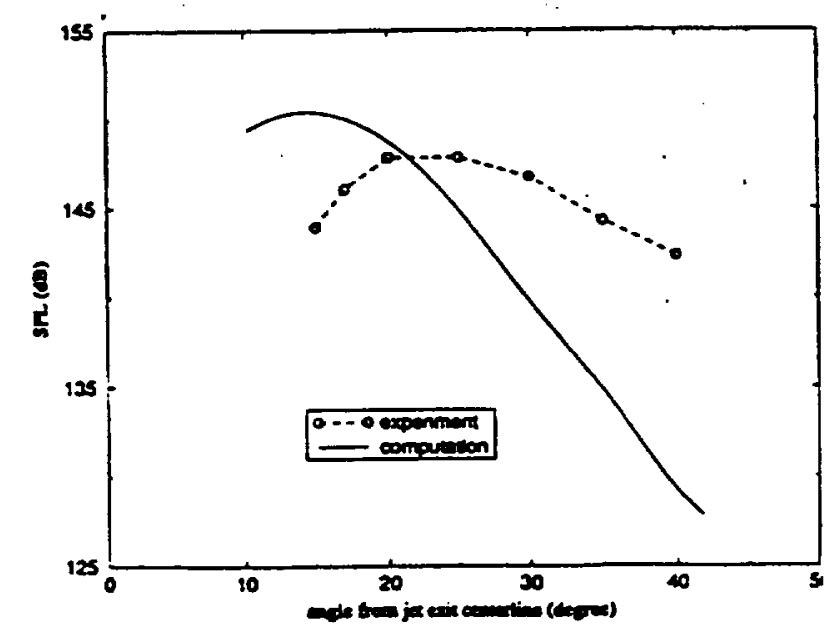

Fig. 12 Directivity of jet noise at $\bar{R} / D=24$. 

Public reporting burden for this collection of information is estimated to average 1 hout per response, including the time for reviewing instructions, searching existing data sources, gathering and maintaining the dala noeded, and completing and reviowing ine colloction of intomation. Send cormments regarding this burden estimate of any other aspect of inis Davis Highway, Sutte 1204, Arlington, VA 22202-4302, and to the Otlice of Management and Budget, Papenwork Reduction Project (0704-0188). Washington, DC 20503.

\begin{tabular}{|l|c|r|}
\hline 1. AGENCY USE ONLY (Leave blank) & $\begin{array}{c}\text { 2. REPORT DATE } \\
\text { March } 1995\end{array}$ & $\begin{array}{r}\text { 3. REPORT TYPE AND DATES COVERED } \\
\text { Technical Memorandum }\end{array}$
\end{tabular}

\section{TITLE AND SUBTITLE}

Direct Computation of Sound Radiation by Jet Flow Using Large-Scale

Equations
5. FUNDING NUMBERS

WU-505-90-5K

6. AUTHOR(S)

R.R. Mankbadi, S.H. Shih, D.R. Hixon, and L.A. Povinelli

\section{PERFORMING ORGANIZATION NAME(S) AND ADDRESS(ES)}

National Aeronautics and Space Administration

Lewis Research Center

Cleveland, Ohio 44135-3191

9. SPONSORING/MONITORING AGENCY NAME(S) AND ADDRESS(ES)

National Aeronautics and Space Administration

Washington, D.C. 20546-0001
8. PERFORMING ORGANIZATION REPORT NUMBER

E-9503
10. SPONSORINGNONITORING AGENCY REPORT NUMBER

NASA TM-106877

ICOMP-95-6

AIAA-95-0680

11. SUPPLEMENTARY NOTES

Prepared for the 33rd Aerospace Sciences Meeting sponsored by the American Institute of Aeronautics and Astronautics, Reno, Nevada, January 9-12,1995. R.R. Mankbadi, NASA Lewis Research Center; S.H. Shih, and D.R. Hixon, Institute for Computational Mechanics in Propulsion, NASA Lewis Research Center (work funded under Cooperative Agreement NCC3-370). ICOMP Program Director, L.A. Povinelli, organization code 2600, (216) 433-5818.

12a. DISTRIBUTIONAVAILABILTY STATEMENT 12b. DISTRIBUTION CODE

Unclassified - Unlimited

Subject Category 34

This publication is available from the NASA Center for Aerospace Information. (301) 621-0390.

13. ABSTRACT (Maximum 200 words)

Jet noise is directly predicted using large-scale equations. The computational domain is extended in order to directly capture the radiated field. As in conventional large-eddy-simulations, the effect of the unresolved scales on the resolved ones is accounted for. Special attention is given to boundary treatment to avoid spurious modes that can render the computed fluctuations totally unacceptable. Results are presented for a supersonic jet at Mach number 2.1.

\begin{tabular}{|c|c|}
\hline \multicolumn{2}{|c|}{$\begin{array}{l}\text { 14. SUBJECT TERMS } \\
\text { Large-scale simulation; Jet noise; Boundary conditions }\end{array}$} \\
\hline $\begin{array}{l}\text { 17. SECURITY CLASSIFICATION } \\
\text { OF REPORT } \\
\text { Unclassified }\end{array}$ & $\begin{array}{l}\text { 18. SECURITY CLASSIFICATION } \\
\text { OF THIS PAGE } \\
\text { Unclassified }\end{array}$ \\
\hline
\end{tabular}

NSN 7540-01-280-5500

\begin{tabular}{|c|c|}
\hline & $\begin{array}{l}\text { 15. NUMBER OF PAGES } \\
12\end{array}$ \\
\hline & $\begin{array}{r}\text { 16. PRICE CODE } \\
\text { A03 }\end{array}$ \\
\hline $\begin{array}{l}\text { 19. SECURITY CLASSIFICATION } \\
\text { OF ABSTRACT } \\
\text { Unclassified }\end{array}$ & 20. LIMITATION OF ABSTRACT \\
\hline
\end{tabular}

Standard Form 298 (Rev. 2-89) Prescribed by ANSI SId. Z39-18 298-102 



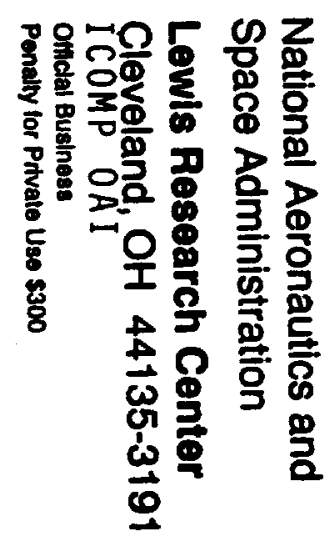

